\title{
Surveillance-Based Program Planning
}

\author{
Rossi Sanusi* \\ Center for Health Service Management, Gadjah Mada University School of Medicine, Yogyakarta, Indonesia
}

\section{Objective}

to analyze the Integrated Behavioral \& Biological Surveillance (IBBS) 2011 data for designing a condom utilization program.

\section{Introduction}

The IBBS is part of the Indonesian MoH HIV Surveillance System, which include Serological Surveillance, Behavioral Surveillance, Reproductive Tract Infection Survey, and monthly HIV/AIDS facilitybased (hospitals, HCs, VCT Sites) monthly reports. The IBBS 2011 was conducted in 11 provinces (22 districts/municipalities) encompassing eight Most At Risk Populations (MARPs) - injection drug users, transsexuals, men who have sex with men, youths, inmates, mobile men, direct female sex workers (FSWs), and indirect FSWs. Data of 442 direct FSWs of the Jayapura Municipality and Jayawijaya District (Papua Province) showed that 406 (91.85\%) have sex with partners who did not use condoms. Of these 406 FSWs $60(14.78 \%)$ were HIV positive and 231 (56.89\%) were STD positive.

\section{Methods}

Items of the Direct FSW Questionnaire, IBBS 2011, were examined and items that would yield information regarding content and method of HIV prevention interventions by means of condoms were identified. The Stata12 software was used to inspect/codebook the variables related to the selected items, to recode numeric data into categorical data, to generate one-way and two-way tables, and to produce pairwise correlations (and their significance levels).

\section{Results}

The Direct FSWs IBBS 2011 data of the Jayapura Municipality and Jayawijaya District showed that there are significant positive correlations between condom use behavior variables of FSWs (i.e., to know, to possess, to buy, and to offer male condoms) and variables of last-sex encounter condom use by customers, and between the latter and HIV and STD lab results. The correlations were low, however, of the condom use behavior variables and variables that are related to comprehensive knowledge of HIV prevention, condom use by more steady sex partners (e.g., husbands, boyfriends, other males) and female condom utilization, and during last-week and last-month sex transactions. The data analyses also indicated details of the distribu- tion of the FSWs, with their condom use behaviors, according to individual characteristics, CIE (communication, information \& education) intervention utilization, condom acquirement, and sexual behavior.

\section{Conclusions}

The condom utilization campaigns ought to focus on continuous reminders (instead of education programs) about how to persuade customers and other sex partners to use condoms, or to allow FSWs to use female condoms, and about where to go for HIV/STD testing and treatment. The condom promotion drives should use posters, TV ads, and field/health workers, The program should also make certain that good quality condoms be made avaible by local managers (of brothels, hotels, bars, etc.) and local vendors (drugists, stands, mobile carts).

\section{Keywords}

IBBS; condom use; HIV; FSWs; Papua

\section{Acknowledgments}

The author thanks the Directorate General of Disease Control \& Environmental Health, MoH, Republic of Indonesia (for allowing to use the IBBS 2011 data) and Family Health Indonesia (for funding the IBBS 2011 Data Analysis Training Program)

\section{References}

Ghimire, L., Smith, W., \& van Teijlingen, E.R. (2011). Utilisation of sexual health services by female sex workers in Nepal. BMC Health Services Research 2011, 11:79.

Longfield, K., Panyanouvong, X., Chen, J., \& Kays, M.B.. (2011). Increasing safer sexual behavior among Lao kathoy through an integrated social marketing approach. BMC Public Health 2011, 11:872.

$\mathrm{MoH}$, Republic of Indonesia. (2011). Report on the Development of HIV \& AIDS in Indonesia until June 2011

*Rossi Sanusi

E-mail: rossi_sanusi@yahoo.com 